\title{
Radiation protection and secondary cancer prevention using biological radioprotectors in radiotherapy
}

\author{
Hamid Abdollahi' ${ }^{1}$, Isaac Shiri ${ }^{1}$, Mohammadreza Atashzar ${ }^{2}$, Maghsoud Sarebani ${ }^{1}$, \\ Kave Moloudi ${ }^{3}$, Hadi Samadian ${ }^{4}$ \\ ${ }^{I}$ Department of Medical Physics, School of Medicine, Iran University of Medical Sciences, Tehran, Iran \\ ${ }^{2}$ Department of Immunology, School of Medicine, Fasa University of Medical Sciences, Fasa, Iran \\ ${ }^{3}$ Department of Radiology, School of Paramedical Sciences, Iran University of Medical Sciences, Tehran, Iran \\ ${ }^{4}$ Department of Medical Nanotechnology, School of Advanced Technologies in Medicine, Tehran University of Medical Sciences, \\ Tehran, Iran
}

Received December 12, 2014; Revised March 12, 2015; Accepted April 05, 2015; Published Online June 08, 2015

\section{Review Article}

\begin{abstract}
Radiotherapy is the feasible treatment approach for many malignant diseases and cancers. New radiotherapy techniques such as ion therapy, stereotactic radiosurgery and intensity modulated radiation therapy deliver higher low dose radiation to large volume of normal tissues and are in debating as more secondary cancers inducers. A secondary cancer after radiotherapy is an important issue that reduces treatment efficiency and should be decreased. Radioprotective compounds are of importance in clinical radiation therapy for saving normal tissues. In the present study, we are so interest to introduce, suggest and review the application of biological radioprotectors in radiotherapy. We propose probiotics, prebiotics, gas, vitamin and nanoparticle producing microorganisms as new biological systems based radioprotectors to protect normal tissues. Also, we reviewed the main biological pathways, molecules and also radioadaptive response that act as radioprotectors. In this review we tried to address the secondary cancer induction by radiotherapy and also main biological radiation protection approaches, although there is a wealth of data in this subject.
\end{abstract}

Keywords: Secondary Cancer; Prevention; Radiotherapy; Biological Radioprotectors

\section{Introduction}

Radiotherapy is the feasible treatment approach for many malignant diseases and cancer. Statistics show the global rate of cancer incidences was 12.7 million cancer cases in $2008{ }^{1}$ and a total of 1,660,290 new cancer cases occur in the United States in $2013^{2}$. Also According to cancer statistics 2015, published by American Cancer Society, "a total of 1,658,370 new cancer cases and 589,430 cancer deaths are projected to occur in the United States in 2015". ${ }^{3}$ Since about half of cancer patients receive radiotherapy as a part of their treatment in curative or palliative modes. ${ }^{4,5}$ In this era, finding the best radiotherapy treatment planning, dose delivery techniques, adaptive radiotherapy tricks, radiation modification and optimization approaches are main concerns as to reduce normal tissues toxicities and increasing tumor control. ${ }^{6-9}$

Many technological attempts have been made and many decisions have been achieved. Physical methods such as ion therapy, stereotactic radiosurgery and intensity modulated radiation therapy (IMRT) opened a new horizon of high dose/quality radiotherapy techniques and achieving more tumor control probability. ${ }^{10-15}$
But, in some methods such as IMRT due to more fields and more monitor units a bigger volume of normal tissue is exposed to lower radiation doses and therefore increases the incidence of secondary cancers in long-term survivors ${ }^{6,7}$ In the other side, exposure due to secondary neutrons as unwanted byproduct in ion therapy could cause a significant risk for developing a secondary cancer later in the patient lifetime. ${ }^{16-18}$

\section{Radiation induced secondary cancer}

A secondary cancer after new and old radiotherapy techniques as an important issue that reduces treatment efficiency is discussed in many literatures. ${ }^{14,16,19-21}$ Secondary cancers are histologically distinct cancers that develop after the first cancer. In United States, secondary cancers are the fourth or fifth most common cancer and account for $6 \%-10 \%$ of all cancer diagnoses. ${ }^{22}$

Radiation induced secondary cancers (RISC) is dependent to many factors including dose level and dose heterogeneity, as 
well as gender and type of tissue irradiated. So, children have a much larger risk to develop RISC. Also, the risk of RISC has formulated and different models with variable parameters such as age of diagnosis and irradiation, radiosensitivity, dose distribution and risk parameters. ${ }^{23,} 24$ These models have many uncertainties in their equations and describing the cancer induction by radiation.

The mechanisms of RISC are very complex and different cellular and molecular processes have been proposed. According to literatures, carcinogenesis has three stages including initiation, promotion and progression. ${ }^{25}$ In these processes, loss and gain of function of vital biological pathways such as $\mathrm{P} 53$ protein activation or inactivation plays the final role. ${ }^{26}$ Speaking generally, when high energy tracks of radiation passes from biological matters, deposited energy may induces direct and indirect effects such as reactive oxygen species (ROS) production and so activation of oxidative stress pathways, DNA damage responses, triggering extra and intracellular mediators and many other responses that causes genomic instability, mutagenesis and carcinogenesis finally. ${ }^{27}$

In recent years, the phenomenon so called "radiation-induced bystander effect" has created a challenging issue among radiation oncologists as a new pathway for RISC. Bystander effect is a non-targeted effect of radiation that refers to "effects detected in cells that were not directly 'hit' by an ionizing radiation track". ${ }^{28}$ In this new debating model of RISC, the chance of carcinogenesis is higher than other classic models, when normal tissues are as bystander organs. So, minimizing the bystander effect in normal tissues has important implications for current and future radiotherapy strategy and procedures. The main proposed mechanisms of bystander effect are: secreted soluble factors, oxidative metabolism, gap-junction intercellular communication, and DNA repair. ${ }^{29,30}$

\section{Radioprotectors}

Finding, testing and applying agents for radiation protection have a historical aspect. There are many different radiation protection/mitigation/modification approaches that based on their nature and mechanisms of action are categorized. Nair and colleagues classified radioprotecting agents into three groups including radioprotectors, adaptogens and absorbents. Radioprotectors are common antioxidants, adaptogens act as stimulators of radioresistance and absorbants protect organisms from internal radiation and chemicals. They also, in a table showed the main mechanisms of radioprotectors are including: free radical scavenging, hydrogen atom donation, immunomodulation/stimulation, electron transfer, detoxification of excess metallic elements, DNA repair and induction and activation of vital mediators such as cytokines and melatonin. ${ }^{31}$
Although, the beneficial effects of radioprotectors are determined in many animal and experimental studies, but their acute toxicities and difficulties in their targeting to normal tissues have caused to a failure in clinical use of these compounds. $^{31}$

In the present study, we are so interest to introduce and suggest the application of biological radioprotectors in radiotherapy. One of the most interesting parts of this study is introducing the microorganisms as radiation protection/mitigation agents their genetically manipulation and targeting them to get the high efficiency.

\section{Biological Radioprotectors}

Biological Radioprotectors (BRPs) can be defined as "any living biological systems and processes that can modify the radiation responses of biological tissues". This definition is based on the biological basis of these agents/pathways and their mechanisms of action that is highly dependent to their characteristics, products and any beneficial changes in their structures.

In this review we divided the BRPs in two different categories including: biological systems (BSBRPs) and biological pathways (BPBRPs). Biological systems are microorganisms including probiotics, gas producing, vitamin producing and those produce nanoparticles. Biological pathways are biological molecules, biochemical processes and ionization radiation induced radiation protection. In microorganism studies, there are no distinct differences between probiotics, gas, vitamin and nanoparticles producing microorganisms and here, we did this categorization to simplify the work. For example a probiotic can be a gas or a vitamin producing microorganism.

\section{Biological systems}

\section{Probiotics}

Probiotics are the first BRPs. ${ }^{32}$ According to the Food and Agriculture Organization of the United Nations (FAO) and the World Health Organization (WHO), probiotics are "live microorganisms which, when administered in adequate amounts, confer a health benefit on the host". ${ }^{33}$ The beneficial effects of probiotic as radioprotectors have obtained from studies that used probiotic to preserve gastrointestinal tract in different radiotherapy patients. ${ }^{34,35}$ Probiotics, also have different abilities such as antioxidant property, toxin neutralization, antagonistic activity, synergistic activity, and stimulation of the immune system ${ }^{36}$ (Kanmani et al., 2013). The main mechanisms of radiation protection using probiotics are induction of NF- $\kappa \mathrm{B}$, the expression of TNF- $\alpha$ and other prion flammatory cytokines, and production of antioxidant enzymes (e.g. superoxide dismutase and catalase) and, therefore, free-radical scavenging. ${ }^{37}$ Combination of probiotic with prebiotics is also has shown promising re- 
sults. ${ }^{38}$ A prebiotic is "a selectively fermented ingredient that allows specific changes, both in the composition and/or activity in the gastrointestinal microflora that confers benefits upon host well-being and health", whereas synergistic combinations of pro- and prebiotics are called synbiotics. ${ }^{39}$

\section{Gas producing microorganisms}

Gas producing microorganisms can be used as second category of BRPs. ${ }^{40,41}$ Some evidences showed that some gases have beneficial effects such as antioxidant properties, radical scavenging, anti-inflammatory, anti-apoptotic and decrease radiosensitivity. These gases are including hydrogen (H2), hydrogen sulphide (H2S), nitric oxide (NO) and carbon monoxide (CO). ${ }^{42,}{ }^{43}$ Several reports have indicated that many microorganisms can produce a wide range of biological gases. Hydrogen producing bacteria are well known for biofuel and safe source of energy. ${ }^{44}$ With regard to life saving roles of hydrogen in radiation sciences such as free radicals scavenging and increase in antioxidant enzymes (such as catalase, superoxide dismutase or heme oxygenase-1), hydrogen producing bacteria can be feasible as BRPs in radiotherapy. The other microorganisms that produce $\mathrm{H} 2, \mathrm{H} 2 \mathrm{~S}, \mathrm{NO}$ and $\mathrm{CO}$ can be used as radioprotectors in radiotherapy. The main interesting part of this study is to use these microorganisms as modifying bystander responses in radiotherapy. It was indicated in different studies that a low concentration of carbon monoxide (CO) can protect cells against death, oxidative injury, inflammation, tolerance of organ transplantation and interestingly, $\mathrm{CO}$ attenuates the production of many factors involved in bystander signaling pathways such as reactive oxygen species (ROS) and Nitric oxide (NO). ${ }^{45}$ So, application of $\mathrm{CO}$ producing bacteria can save normal tissues from bystander signals and subsequent radiobiological damages.

\section{Vitamin producing microorganisms}

Vitamin producing microorganisms are very interesting. There are well established papers that indicated several microorganisms such as bacteria can produce different kinds of vitamins including $\mathrm{C}, \mathrm{E}, \mathrm{K}$ and $\mathrm{B}$-complex. ${ }^{46-48}$ Vitamins are essential nutrients as precursors of various enzymes that are necessary for vital biochemical reactions in all living cells. Also vitamins can act as antioxidant agents.

Scientific evidences implicate the involvement of reactive oxygen species (ROS) in cancer development by inducing DNA mutations, genomic instability, and activation of biochemical pathways that stimulate proliferation and neoplastic transformation. ${ }^{49}$ ROS are highly reactive molecules that are produced by normal cellular metabolism and environmental factors such as radiation, and can damage DNA and proteins. "Oxidative stress" is a shift in the balance between oxidants and antioxidants materials. According to relation between oxidative stress and cancer, consumption of antioxidants such as vitamins $\mathrm{E}$ and $\mathrm{C}$ is useful in preventing carcinogenesis and inflammation related carcinogenesis.
Humans are incapable of synthesizing most vitamins and they have to be obtained from exogenous sources. One the most interesting part of these exogenous agents is microorganisms. Microorganisms such as bacteria are well known as source of vitamin production. So, they can be used as radioprotectors in radiotherapy for secondary cancer prevention. The use of vitamin-producing microorganisms may represent a more natural and patient-friendly alternative to radioprotection using chemically synthesized radioprotectors, and would allow the production of radioprotectors with elevated concentrations of vitamins that are less likely to cause undesirable side-effects.

\section{Nanoparticle producing microorganisms}

Nanotechnology is a multidisciplinary field that involves the design and engineering of objects $<100$ nanometers in size. In recent years many nanoparticles have been used to reduce radiation damages in biological systems. ${ }^{50-53}$ The role of nanoparticles as radioprotectors is a cutting-edge development addressing decades of scientific interest regarding the protection of normal cells and tissues from radiation. Experiments in living cells and in vivo have demonstrated the efficiency of the nanoparticles in radiation protection. A new generation of free radical scavengers is nanoparticles. The most significant nanoparticles used for radiation protection are silver (Ag) ${ }^{54,56}$ and cerium oxide (CeO2) ${ }^{50,51}$. The therapeutic values of nanoparticles are due to their free radical scavenging properties. Also nanoparticles as scavenging enzymes are many times more efficient than radical scavenging enzymes, which may be due to the large surface area to volume ratio. $^{56,57}$

There are many physical, chemical, biological and hybrid methods to produce different types of nanoparticles. ${ }^{58-60} \mathrm{De}-$ velopment of nontoxic and biocompatible nanoparticles is of utmost importance to expand their biomedical applications. One of the options to achieve this goal is to use microorganisms to synthesize nanoparticles. ${ }^{61}$ Many microorganisms and plants can produce nanoparticles by intracellular or extracellular routes. For silver nanoparticle production, different microbes reduce the Ag+ ions to form spherical silver nanoparticles. For example, bacterium Pseudomonas stutzeri AG259, present at silver mine, when placed in a concentrated aqueous solution of silver nitrate, played a major role in the reduction of the $\mathrm{Ag}+$ ions and the formation of silver nanoparticles of well-defined size and distinct topography within the periplasmic space of the bacteria. ${ }^{62}$ The most important requirement for an organism to produce silver nanoparticle is to be resistant against silver ions. Also, organisms which synthesize silver nanoparticles are also vulnerable to higher concentrations of silver ions. ${ }^{63}$

With regard to microorganisms' BSBRPs it is important to be ensuring that they have been administrated in safe dose and the rules of administration, targeting and patient involved 
have been well determined. In this approach, the important issues are: 1) preparing the BSBRPs in safe modes, 2) finding the main microorganisms that have high efficiencies as BSBRPs, 3) administrations and targeting them and 4) biotechnological manipulation of them to have the highest efficiency.

TABLE 1: Shows various species of microorganisms synthesizing silver nanoparticles.

\begin{tabular}{lll}
\hline \hline Organism & Type & Reference \\
\hline Pseudomonas stutzeri AG259 & Bacteria & $(62)$ \\
Lactobacillus Strains & Bacteria & $(64)$ \\
Bacillus megaterium & Bacteria & $(65)$ \\
Bacillus licheniformis & Bacteria & $(66)$ \\
Brevibacterium casei & Bacteria & $(67)$ \\
Staphylococcus aureus & Bacteria & $(68)$ \\
Geobacter sulfurreducens & Bacteria & $(69)$ \\
Aspergillus clavatus & Fungi & $(70)$ \\
Fusarium solani & Fungi & $(71)$ \\
Fusarium oxysporum & Fungi & $(72)$ \\
Aspergillus flavus & Fungi & $(73)$ \\
Trichoderma viride & Fungi & $(74)$ \\
Cladosporium cladosporioides & Fungi & $(75)$ \\
Phanerochaete chrysosporium & Fungi & $(76)$ \\
Azadirachta indica & Plant & $(77)$ \\
Cinnamomum camphora leaf & Plant & $(78)$ \\
Phyllanthus amarus & Plant & $(79)$ \\
Carica papaya & Plant & $(80)$ \\
Coriandrum sativum leaf extract & Plant & $(81)$ \\
Jatropha curcas & Plant & $(82)$ \\
Glycine max (soybean) leaf extract & Plant & $(83)$ \\
\hline \hline
\end{tabular}

There are different methods to preparing BSBRPs in enough amounts. For example Yin and colleague's showed that in comparison with the conventional pretreatment methods, such as heat-shock, acid, base, aeration and chloroform, gamma irradiation was more powerful pretreatment method for enriching hydrogen-producing bacteria. ${ }^{84}$ In the case of probiotics and prebiotics, they are available commercially in many forms, including foods, dietary supplements, and clinical therapeutics with oral or non-oral delivery. A feasible BSBRPs must retain its properties during preparation and remain viable and stable during storage and use. In the other hand, it should be noted that there are some challenging interactions between BRPs and drugs. Because BSBRPs contain live microorganisms, concurrent administration of some drugs such as antibiotics could kill a large number of the organisms, and the efficacy of this radioprotectors may be reduced.

The main advantages of BSBRPs in comparison to other radioprotectors is their biotechnologically manipulation. As their genetic materials, it is established approach to change microorganisms to become safer and produce more radiation protection agents. In addition, by genetic manipulations, we can deliver BRPs to normal tissues specifically. In this light, by removing genes-encoding proteins which are involved in the pathogenesis, the safety of BRPs can be obtained.

\section{Biological pathways}

\section{Biological molecules and Biochemical processes}

Radiation interaction with biological matters triggers different molecules, pathways and biochemical processes that lead to cells death and repair. The main aim of those triggered systems is to maintain and keep hemostasis well. In this situation, these systems can be used as biological radioprotectants. Here, we review and introduce some of which are present or have been applied invivo or invitro to reduce radiation damages.

Interterleukins (ILs) are naturally occurring proteins that mediate communication between cells. Interleukins regulate cell growth, differentiation, and motility. They are particularly important in stimulating immune responses, such as inflammation. Different studies show various types of ILs has radioprotective properties. Schwarz et al. showed IL-12 protect cells from apoptosis induced by DNA-damaging radiation by inducing DNA repair, and that nucleotide-excision repair can be manipulated by cytokines ${ }^{85}$ Also, Xiong et al. study showed recombinant human like interleukin 12 (rhIL-12) can promote the bone marrow hematopoietic stem/progenitor cell colony formation in vitro and protect lethally-irradiated monkeys. ${ }^{86}$

Studies showed that interleukin 1 (IL 1), a potent in vivo stimulator of hemopoiesis which acts as a differentiation-and maturation-inducing agent for a variety of cells can serve as a signal that initiates radioprotective events in vivo and then protects mice in a dose-dependent manner from lethal effects of ionizing radiation. ${ }^{87}$ There is a report that showed pretreatment of small intestinal clonogenic stem cells with Interleukin 11 can moderate radiation induced damages and increased survival. ${ }^{88}$

There are some different cytokines that have been produced in response to radiation and bind to the same receptors and have pleiotropic effects on a variety of cell types. Tumor necrosis factor (TNF) and lymphotoxin (LT) are these cytokines which can induce the synthesis of protective proteins such as mitochondrial manganese superoxide dismutase (MnSOD), protects animals from radiation. ${ }^{89}$ Metallothioneins (MTs) are intracellular and low molecular weight cysteine-rich proteins. They have unique structural characteristics to give potent metal-binding and redox capabilities. A striking resistance to lethal damage from radiation has been found in mice which had received various pretreatments to induce metallothionein synthesis in the liver prior to irradiation. ${ }^{90}$

Melatonin (N-acetyl-5-methoxytryptamine), an endogenous compound synthesized by the pineal gland in the human brain plays a vital role in the regulation of a number of physiological and pathological processes. ${ }^{91}$ Melatonin is a 
free radical scavenger and stimulates antioxidant activities of antioxidant enzymes such as glutathione peroxidase (GSH-Px), glutathione reductase (GR), superoxide dismutase (SOD), and catalase (CAT). Several studies in various organs and cells have showed that melatonin can reduce irradiation-induced injuries. ${ }^{92-94}$

In signaling pathways, inhibition of CD47 signaling, protect normal tissues after irradiation and increases the radiosensitivity of tumors. ${ }^{95}$ Also, transcription factor NF- $\kappa \mathrm{B}$ has a radioprotection role against radiation-induced apoptosis in the intestinal epithelium.

\section{Ionization radiation induced radiation protection}

Although radiation is a physical modality, but here we remember it as a biological radioprotector, because it protects cells by enhancing the main biological pathways of radiation protection. There is a wealth of data showing a low level of radiation can induce so called "radioadaptive response" that during which biological systems which received a low dose of radiation become more resistant against any challenge dose of harmful agents (such as radiation). The main mechanism of radioadaptive response is unknown, but different experimental invivo/invitro studies by various endpoints have showed transcription of many genes and activation of numerous signaling pathways that trigger cell defenses more efficient detoxification of free radicals, DNA repair systems, induction of new proteins, enhanced antioxidant production, alteration in expression of genes associated with cell cycle regulation, DNA repair, signal transduction, apoptosis induction/tumorigenesis and damage response/ maintenance of genetic stability (P53-related functions), activation of protein kinase $\mathrm{C}$ through p38 MAP kinase resulting in P53, ERK, JNK kinases and WIP phosphatase activation and Ribose Polymerase-1 (PARP) activation ${ }^{96}$.

Abdollahi in interesting paper suggested that "cellular autofluorescence following ionization radiation can activate some synthetic drugs called photoactivated agents that are injected in human body after radiation exposures scenarios. Photo activated agents can activate biological pathways such as DNA repair and immune stimulation pathways, bystander signals blocking, and so survive cells and tissues". This approach based on the fact many different human and murine cell types respond to ionizing radiation with a striking rise in autofluorescence that is dependent on dose and time. In this situation, light emitted from cellular response to irradiation can act as a natural factor to activate some special drugs to enhance radioprotective mechanisms. ${ }^{97}$

In relation to radioadaptive response, it should be mentioned that no radiation (any level if low) should be used. The main of this radiation protection approach is to enhance radioprotective mechanisms that have been activated by radiation.

\section{Conclusion}

Radioprotective compounds are of importance in clinical radiation therapy. In this study we introduced, suggested and reviewed biological radioprotectors as new agents for saving normal tissues in radiotherapy and so reducing the risk of secondary cancers after treatment. Probiotics, prebiotics gas and vitamin producing microorganisms introduced as new biological radioprotectors. Applications of these agents need more clinical trials, but by genomics, proteomics and new biotechnological advances we can find the highest outcomes.

These radioprotectors can act as antioxidants, anti-inflammation, anti-apoptosis, anti-aging agents and they also can decrease radiosensitivity and bystander cell death signals. In the other hand, genetically manipulation and targeting of biological radioprotectors can resulted to the highest efficiency. To improve the efficacy and safety of BSBRPs, a further understanding of microorganisms between with immune system are required. Genomics, proteomics and new biotechnological advances may help to highest outcomes be achieved. Also, biological pathways of radiation protection should be enhanced or amplified by many biocompatible agents.

\section{Conflict of interest}

The authors declare that they have no conflicts of interest. The authors alone are responsible for the content and writing of the paper.

\section{References}

1. Jemal A, Bray F, Center MM, et al. Global cancer statistics. CA Cancer J Clin 2011; 61:69-90.

2. Siegel R, Naishadham D, Jemal A. Cancer statistics, 2013. CA Cancer J Clin 2013; 63:11-30.

3. Siegel RL, Miller KD, Jemal A. Cancer Statistics, 2015. CA Cancer J Clin 2015; 65:5-29.

4. Sawant S, Shegokar R. Cancer research and therapy: Where are we today? Int J Cancer Ther Oncol 2014; 2:02048.

5. Jones JA, Lutz ST, Chow E, Johnstone PA. Palliative radiotherapy at the end of life: A critical review. CA Cancer J Clin 2014; 64:295-310.

6. Carter HE, Martin A, Schofield D, et al. A decision model to estimate the cost-effectiveness of intensity modulated radiation therapy (IMRT) compared to three dimensional conformal radiation therapy (3DCRT) in patients receiving radiotherapy to the prostate bed. Radiother Oncol 2014; 112:187-93. 
7. Lu L. Dose calculation algorithms in external beam photon radiation therapy. Int J Cancer Ther Oncol 2013; 1:01025.

8. Petrou EI, Narayanasamy G, Lavdas E, et al. Evaluation of the generalized gamma as a tool for treatment planning optimization. Int J Cancer Ther Oncol 2014; 2:020418.

9. Thirumalai-Swamy S, Anuradha C, Kathirvel M, et al. Pretreatment quality assurance of volumetric modulated arc therapy on patient CT scan using indirect 3D dosimetry system. Int J Cancer Ther Oncol 2014; 2:020416.

10. Ulmer W. Notes of the editorial board on the role of medical physics in radiotherapy. Int J Cancer Ther Oncol 2013; 1:01014.

11. Rana S, Pokharel S, Zheng Y, et al. Treatment planning study comparing proton therapy, RapidArc and intensity modulated radiation therapy for a synchronous bilateral lung cancer case. Int J Cancer Ther Oncol 2014;2:020216.

12. Al-Tonbary Y. Recent advances in treatment of childhood cancer: role of targeted therapy. Int J Cancer Ther Oncol 2013; 1:01028.

13. Rana S, Cheng C, Zheng Y, et al. Dosimetric study of uniform scanning proton therapy planning for prostate cancer patients with a metal hip prosthesis, and comparison with volumetric-modulated arc therapy. J Appl Clin Med Phys 2014; 15:4611.

14. Newhauser WD, Durante M. Assessing the risk of second malignancies after modern radiotherapy. Nat Rev Cancer 2011;11:438-48.

15. Salama JK, Kirkpatrick JP, Yin FF. Stereotactic body radiotherapy treatment of extracranial metastases. Nat Rev Clin Oncol 2012; 9:654-65.

16. Paganetti H, Athar BS, Moteabbed M, et al. Assessment of radiation-induced second cancer risks in proton therapy and IMRT for organs inside the primary radiation field. Phys Med Biol 2012; 57:6047.

17. Zelefsky MJ, Housman DM, Pei X, et al. Incidence of secondary cancer development after high-dose intensity-modulated radiotherapy and image-guided brachytherapy for the treatment of localized prostate cancer. Int J Radiat Oncol Biol Phys 2012; 83:953-9.

18. Islam MR. Secondary neutrons issue in proton radiotherapy-a brief report. Int J Cancer Ther Oncol 2014; 2:02017.

19. Lee B, Lee S, Sung J, Yoon M.

Radiotherapy-induced secondary cancer risk for breast cancer: 3D conformal therapy versus IMRT versus VMAT. J Radiol Prot 2014; 34:325.

20. Harbron RW, Feltbower RG, Glaser A, et al. Secondary malignant neoplasms following radiotherapy for primary cancer in children and young adults. Pediatr Hematol Oncol 2014; 31:259-67.

21. Berrington de Gonzalez A, Wong J, Kleinerman R, et al. Risk of second cancers according to radiation therapy technique and modality in prostate cancer survivors. Int J Radiat Oncol Biol Phys 2015; 91:295-302.

22. Schneider U. Modeling the risk of secondary malignancies after radiotherapy. Genes 2011; 2:1033-49.

23. Simone CB $2^{\text {nd }}$, Kramer K, O'Meara WP, et al. Predicted rates of secondary malignancies from proton versus photon radiation therapy for stage I seminoma. Int J Radiat Oncol Biol Phys 2012; 82:242-9.

24. Brodin NP, Munck Af Rosenschöld P, Aznar MC, et al. Radiobiological risk estimates of adverse events and secondary cancer for proton and photon radiation therapy of pediatric medulloblastoma. Acta Oncol 2011; 50:806-16.

25. Ziech D, Franco R, Pappa A, Panayiotidis MI. Reactive Oxygen Species (ROS)-Induced genetic and epigenetic alterations in human carcinogenesis. Mutat Res 2011; 711:167-73.

26. Muller PA, Vousden KH. Mutant p53 in cancer: new functions and therapeutic opportunities. Cancer cell 2014; 25:304-17.

27. Shah DJ, Sachs RK, Wilson DJ. Radiation-induced cancer: a modern view. BrJ Radiol 2012; 85:e1166-73.

28. Mothersill C, Seymour C. Radiation-induced bystander effects, carcinogenesis and models. Oncogene 2003; 22:7028-33.

29. Prise KM, O'Sullivan JM. Radiation-induced bystander signalling in cancer therapy. Nat Rev Cancer 2009; 9:351-60.

30. Hei TK, Zhou H, Ivanov VN, et al. Mechanism of radiation-induced bystander effects: a unifying model. J Pharm Pharmacol 2008; 60:943-50.

31. Nair CK, Parida DK, Nomura T. Radioprotectors in radiotherapy. J Radiat Res 2001; 42:21-37.

32. Abdollahi H. Probiotic-based protection of normal tissues during radiotherapy. Nutrition 2014; 30:495-6.

33. Araya M, Morelli L, Reid G, et al. Guidelines for the evaluation of probiotics in food. Joint FAO/WHO Working Group report on drafting 
guidelines for the evaluation of probiotics in food, London; (ON, Canada) 2002.

ftp://ftp.fao.org/es/esn/food/wgreport2.pdf

34. Mego M, Holec V, Drgona L, et al. Probiotic bacteria in cancer patients undergoing chemotherapy and radiation therapy. Complement Ther Med 2013; 21:712-23.

35. Theis VS, Sripadam R, Ramani V, Lal S. Chronic radiation enteritis. Clin Oncol. 2010; 22:70-83.

36. Kanmani P, Satish Kumar R, Yuvaraj N, et al. Probiotics and its functionally valuable products-a review. Crit Rev Food Sci Nutr. 2013; 53:641-58.

37. Dai C, Zheng CQ, Meng FJ, et al. VSL\#3 probiotics exerts the anti-inflammatory activity via PI3k/Akt and NF- $\mathrm{BB}$ pathway in rat model of DSS-induced colitis. Mol Cell Biochem 2013; 374:1-11.

38. Hamad A, Fragkos KC, Forbes A. A systematic review and meta-analysis of probiotics for the management of radiation induced bowel disease. Clin Nutr 2013; 32:353-60.

39. Roberfroid M. Prebiotics: the concept revisited. J Nutr 2007; 137:830S-7S.

40. Khademi S, Abdollahi H. Application of Hydrogen Producing Microorganisms in Radiotherapy: An Idea. Iran J Public Health 2014; 43:1018-9.

41. Abdollahi H, Atashzar M, Amini M. The potential use of biogas producing microorganisms in radiation protection. JMed Hypotheses Ideas 2015; 2:67-71.

42. Schoenfeld MP, Ansari RR, Nakao A, Wink D. A hypothesis on biological protection from space radiation through the use of new therapeutic gases as medical counter measures. Med Gas Res 2012; 2.

43. Schoenfeld MP, Ansari RR, Zakrajsek JF, et al. Hydrogen therapy may reduce the risks related to radiation-induced oxidative stress in space flight. Medical Hypotheses 2011; 76:117-8.

44. Liu H, Wang G. Fermentative hydrogen production from macro-algae Laminaria japonica using anaerobic mixed bacteria. International Journal of Hydrogen Energy 2014; 39:9012-7.

45. Han W, Yu KN, Wu LJ, et al. Mechanism of protection of bystander cells by exogenous carbon monoxide: Impaired response to damage signal of radiation-induced bystander effect. Mutat Res 2011; 709:1-6.

46. LeBlanc JG, Laiño JE, del Valle MJ, et al. B-group vitamin production by lactic acid bacteria-current knowledge and potential applications. J Appl Microbiol 2011;111:1297-309.
47. LeBlanc JG, Milani C, de Giori GS, et al. Bacteria as vitamin suppliers to their host: a gut microbiota perspective. Curr Opin Biotechnol 2013; 24:160-8.

48. Ray AK, Ghosh K, Ringø E. Enzyme-producing bacteria isolated from fish gut: a review. Aquaculture Nutrition 2012; 18: 465-92.

49. Reuter S, Gupta SC, Chaturvedi MM, Aggarwal BB. Oxidative stress, inflammation, and cancer: how are they linked? Free Radic Biol Med 2010; 49:1603-16.

50. Colon J, Herrera L, Smith J, et al. Protection from radiation-induced pneumonitis using cerium oxide nanoparticles. Nanomedicine 2009; 5:225-31.

51. Colon J, Hsieh N, Ferguson A, et al. Cerium oxide nanoparticles protect gastrointestinal epithelium from radiation-induced damage by reduction of reactive oxygen species and upregulation of superoxide dismutase 2. Nanomedicine 2010; 6:698-705.

52. Tarnuzzer RW, Colon J, Patil S, Seal S. Vacancy engineered ceria nanostructures for protection from radiation-induced cellular damage. Nano Lett 2005;5:2573-7.

53. Schweitzer AD, Revskaya E, Chu P, et al. Melanin-covered nanoparticles for protection of bone marrow during radiation therapy of cancer. Int J Radiat Oncol Biol Phys 2010; 78:1494-502.

54. Chandrasekharan DK, Khanna PK, Kagiya TV, Nair CKK. Synthesis of nanosilver using a vitamin C derivative and studies on radiation protection. Cancer Biother Radiopharm 2011; 26:249-57.

55. Chandrasekharan DK, Nair CKK. Studies on Silver Nanoparticle-Glycyrrhizic Acid Complex as a Radioprotector and an Adjuvant in Radiotherapy Under In Vivo Conditions. Cancer Biother Radiopharm 2012; 27:642-51.

56. Kajita M, Hikosaka K, Iitsuka M, et al. Platinum nanoparticle is a useful scavenger of superoxide anion and hydrogen peroxide. Free Radic Res 2007; 41:615-26.

57. Reddy MK, Wu L, Kou W, et al. Superoxide dismutase-loaded PLGA nanoparticles protect cultured human neurons under oxidative stress. Appl Biochem Biotechnol 2008; 151:565-77.

58. Lu AH, Salabas EL, Schüth F. Magnetic nanoparticles: synthesis, protection, functionalization, and application. Angew Chem Int Ed Engl 2007; 46:1222-44.

59. Song JY, Kim BS. Rapid biological synthesis of silver nanoparticles using plant leaf extracts. Bioprocess Biosyst Eng 2009; 32:79-84. 
60. Fedlheim DL, Foss CA. Metal nanoparticles: synthesis, characterization, and applications: CRC Press; 2001.

61. Iravani S. Bacteria in nanoparticle synthesis: Current status and Future prospects. International Scholarly Research Notices 2014; 2014.

62. Klaus T, Joerger R, Olsson E, Granqvist C-G. Silver-based crystalline nanoparticles, microbially fabricated. Proceedings of the National Academy of Sciences 1999; 96:13611-4.

63. Parikh RY, Singh S, Prasad B, et al. Extracellular synthesis of crystalline silver nanoparticles and molecular evidence of silver resistance from Morganella sp.: towards understanding biochemical synthesis mechanism. Chem Bio Chem 2008; 9:1415-22.

64. Nair B, Pradeep T. Coalescence of nanoclusters and formation of submicron crystallites assisted by Lactobacillus strains. Crystal Growth \& Design 2002;2:293-8.

65. Fu JK, Zhnag WD, Liu YY, et al. Characterization of adsorption and reduction of noble metal ions by bacteria. Chem J Chin Univ 1999;20:1454-6.

66. Kalishwaralal K, Banumathi E, Pandian SRK, et al. Silver nanoparticles inhibit VEGF induced cell proliferation and migration in bovine retinal endothelial cells. Colloids Surf B Biointerfaces 2009; 73:51-7.

67. Kalishwaralal K, Deepak V, Ram Kumar Pandian S, et al. Biosynthesis of silver and gold nanoparticles using Brevibacterium casei. Colloids Surf B Biointerfaces 2010; 77:257-62.

68. Nanda A, Saravanan M. Biosynthesis of silver nanoparticles from Staphylococcus aureus and its antimicrobial activity against MRSA and MRSE. Nanomedicine 2009; 5:452-6.

69. Law N, Ansari S, Livens FR, et al. Formation of nanoscale elemental silver particles via enzymatic reduction by Geobacter sulfurreducens. Appl Environ Microbiol 2008; 74:7090-3.

70. Verma VC, Kharwar RN, Gange AC. Biosynthesis of antimicrobial silver nanoparticles by the endophytic fungus Aspergillus clavatus. Nanomedicine 2010; 5:33-40.

71. Ingle A, Rai M, Gade A, Bawaskar M. Fusarium solani: a novel biological agent for the extracellular synthesis of silver nanoparticles. J Nanopart Res 2009; 11:2079-85.

72. Ahmad A, Mukherjee P, Senapati S, et al. Extracellular biosynthesis of silver nanoparticles using the fungus Fusarium oxysporum. Colloids Surf B Biointerfaces 2003; 28:313-8.
73. Vigneshwaran N, Ashtaputre NM, Varadarajan PV, et al. Biological synthesis of silver nanoparticles using the fungus Aspergillus flavus. Materials letters 2007; 61:1413-8.

74. Fayaz M, Tiwary CS, Kalaichelvan PT, Venkatesan R. Blue orange light emission from biogenic synthesized silver nanoparticles using Trichoderma viride. Colloids Surf B Biointerfaces 2010; 75:175-8.

75. Balaji DS, Basavaraja S, Deshpande R, et al. Extracellular biosynthesis of functionalized silver nanoparticles by strains of Cladosporium cladosporioides fungus. Colloids Surf B Biointerfaces 2009; 68:88-92.

76. Vigneshwaran N, Kathe AA, Varadarajan PV, et al. Biomimetics of silver nanoparticles by white rot fungus, Phaenerochaete chrysosporium. Colloids Surf B Biointerfaces 2006; 53:55-9.

77. Shankar SS, Rai A, Ahmad A, Sastry M. Rapid synthesis of $\mathrm{Au}, \mathrm{Ag}$, and bimetallic Au core-Ag shell nanoparticles using Neem (Azadirachta indica) leaf broth. J Colloid Interface Sci 2004; 275:496-502.

78. Huang J, Li Q Sun D, et al. Biosynthesis of silver and gold nanoparticles by novel sundried Cinnamomum camphora leaf. Nanotechnology 2007;18:105104.

79. Kasthuri J, Kathiravan K, Rajendiran N. Phyllanthin-assisted biosynthesis of silver and gold nanoparticles: a novel biological approach. Journal of Nanoparticle Research 2009; 11:1075-85.

80. Mude N, Ingle A, Gade A, Rai M. Synthesis of silver nanoparticles using callus extract of Carica papaya-a first report. J Plant Biochemistry \& Biotechnology 2009; 18:83-6.

81. Sathyavathi R, Krishna MB, Rao SV, et al. Biosynthesis of silver nanoparticles using Coriandrum sativum leaf extract and their application in nonlinear optics. Advanced science letters 2010; 3:138-43.

82. Bar H, Bhui DK, Sahoo GP, et al. Green synthesis of silver nanoparticles using seed extract of Jatropha curcas. Colloids and Surfaces A: Physicochemical and Engineering Aspects 2009; 348:212-6.

83. Vivekanandhan S, Misra M, Mohanty AK. Biological synthesis of silver nanoparticles using Glycine max (soybean) leaf extract: an investigation on different soybean varieties. J Nanosci Nanotechnol 2009; 9:6828-33.

84. Yin Y, Hu J, Wang J. Gamma irradiation as a pretreatment method for enriching hydrogen-producing bacteria from digested sludge. 
International Journal of Hydrogen Energy 2014; 39:13543-9.

85. Schwarz A, Ständer S, Berneburg M, et al. Interleukin-12 suppresses ultraviolet radiation-induced apoptosis by inducing DNA repair. Nat Cell Biol 2002; 4:26-31.

86. Xiong GL, Zhao Y, Xing S, et al. Radiation protection effect of rhIL-12 on monkey hematopoietic system. Zhongguo Shi Yan Xue Ye Xue Za Zhi 2013;21:150-4.

87. Neta R, Douches S, Oppenheim JJ. Interleukin 1 is a radioprotector. J Immunol 1986;136:2483-5.

88. Potten CS. Protection of the Small Intestinal Clonogenic Stem Cells from Radiation-Induced Damage by Pretreatment with Interleukin 11 also Increases Murine Survival Time. Stem Cells 1996;14:452-9.

89. Wong GH, Kaspar RL, Vehar G. Tumor necrosis factor and lymphotoxin: protection against oxidative stress through induction of MnSOD. EXS 1996;77:321-33.

90. Matsubara J, Tajima Y, Karasawa M. Metallothionein induction as a potent means of radiation protection in mice. Radiat Res 1987;111:267-75.

91. Mihandoost E, Shirazi A, Mahdavi SR, Aliasgharzadeh A. Can melatonin help us in radiation oncology treatments? Biomed Res Int 2014;2014:578137.

92. Koc M, Taysi S, Buyukokuroglu ME, Bakan N. Melatonin protects rat liver against irradiation-induced oxidative injury. J Radiat Res 2003;44:211-5.

93. Vijayalaxmi, Reiter RJ, Meltz ML. Melatonin protects human blood lymphocytes from radiation-induced chromosome damage. Mutat Res 1995;346:23-31.

94. Vijayalaxmi, Reiter RJ, Tan DX, et al. Melatonin as a radioprotective agent: a review. Int J Radiat Oncol Biol Phys 2004;59:639-53.

95. Maxhimer JB, Soto-Pantoja DR, Ridnour LA, et al. Radioprotection in normal tissue and delayed tumor growth by blockade of CD47 signaling. Sci Transl Med 2009;1:3ra7.

96. Dimova EG, Bryant PE, Chankova SG. Adaptive response: some underlying mechanisms and open questions. Genet Mol Biol 2008;31:396-408.

97. Abdollahi H. Beneficial effects of cellular autofluorescence following ionization radiation: hypothetical approaches for radiation protection and enhancing radiotherapy effectiveness. Med Hypotheses 2015;84:194-8. 